\title{
Dilution Ratio and Particle Loss Performance of a Newly Developed Ejector Porous Tube Diluter Compared to a Commercial Diluter
}

\author{
Dongho Shin ${ }^{1,3}$, Hyunsoo Seo1, Kee-Jung Hong1, Hak-Joon Kim¹, Yong-Jin Kim¹, \\ Bangwoo Han ${ }^{*}$, Ga-Young Lee ${ }^{2}$, Sung-Nam Chun², Jungho Hwang ${ }^{3 * *}$ \\ ${ }^{1}$ Department of environment Machinery, Korea Institute of Machinery \& Materials, Daejeon 34103, Korea \\ ${ }^{2}$ Korea Electric Power Research Institute, Daejeon 305-380, Korea \\ ${ }^{3}$ Mechanical Engineering, Yonsei University, Seoul 038722, Korea
}

\begin{abstract}
In this study, a new ejector-porous tube diluter was developed to accurately in situ measure particulate matter at the source, e.g., emissions at coal-fired power plants, and its dilution ratio and particle loss were compared to those of a commercial model. Whereas commercial models supply air to the porous tube diluter (PRD) using a high-pressure compressor, our device replaces the latter with a ring blower, thereby decreasing the power consumption for the same airflow rate. As a demonstration, particle size volume distributions of fly ash at a coal-fired power plant stack were determined for different dilution ratios. PRD flow rates of 10 and $20 \mathrm{~L} \mathrm{~min}^{-1}$ for the commercial diluter produced $\sim 2-\mu \mathrm{m}$ particle volume concentrations of 382 and $572 \mu \mathrm{m}^{3} \mathrm{~cm}^{-3}$, respectively, from an initial (undiluted) volume concentration of $756 \mu \mathrm{m}^{3} \mathrm{~cm}^{-3}$. However, PRD flow rates of 10 and $30 \mathrm{~L} \mathrm{~min}^{-1}$ for the developed device produced $\sim 2-\mu \mathrm{m}$ particle volume concentrations of 506 and $500 \mu \mathrm{m}^{3} \mathrm{~cm}^{-3}$, respectively, from an initial volume concentration of $532 \mu \mathrm{m}^{3} \mathrm{~cm}^{-3}$. These particle loss rates were confirmed through field testing.
\end{abstract}

Keywords: Diluter; Ejector; Porous tube; Particle loss; Turbulence.

\section{INTRODUCTION}

Public interest in fine particles, particularly exhaust emissions from industrial combustion facilities (e.g., coalfired power plants), has increased recently because said facilities are a large source of particulate matter (PM) emissions in South Korea (Davidson et al., 2007; Kim and Zhang, 2019). Therefore, the Korean government is gradually strengthening the PM emission standards for air pollutant exhaust facilities from $20-25$ to $10-12 \mathrm{mg} \mathrm{m}^{-3}$. To successfully implement this standard, step-wise improvements are essential. Most importantly, accurate measurement of $\mathrm{PM}$ at the source is required. Currently, telemonitoring systems (TMSs) are continuously monitoring air pollutants, including total suspended particles (TSPs), $\mathrm{NO}_{x}, \mathrm{SO}_{x}, \mathrm{HCl}$, $\mathrm{HF}, \mathrm{NH}_{3}$, and $\mathrm{CO}$, from several stacks of high-emitting facilities. However, TMSs based on light transmission methods

\footnotetext{
* Corresponding author.

Tel.: 82-42-868-7068; Fax: 82-42-868-7284

E-mail address: bhan@kimm.re.kr

** Corresponding author.

Tel.: Tel: 82-2-2123-7226; Fax: 82-2-312-2821

E-mail address: hwangjh@yonsei.ac.kr
}

only measure TSPs and cannot measure coarse $\left(\mathrm{PM}_{10}\right)$ and fine $\left(\mathrm{PM}_{2.5}\right)$ particles separately. The current method used to measure $\mathrm{PM}_{10}$ and $\mathrm{PM}_{2.5}$ concentrations in stacks is based on a gravimetric approach that requires several days to obtain sufficient mass concentration data. Optical particle counters (OPCs) (Chien et al., 2016), Scanning Mobility Particle Sizers (SMPSs; Mariam et al., 2017), and Aerodynamic Particle Sizers (APSs) are real-time particle measuring instruments. However, because most industrial combustion facility stacks are characterized by high temperatures and particle concentrations, the use of diluters is essential to reduce the temperature $\left(0-40^{\circ} \mathrm{C}\right)$ and particle concentrations to a measurable range.

Commercial diluters include rotating-disk (Zhang et al., 2014), porous tube (Woo et al., 2017), and ejector-type diluters (Wong et al., 2003). Most industrial combustion facilities use diluters that combine porous-tube and ejector technologies to measure the particle sizes from exhaust (Lipsky et al., 2002; Li et al., 2011; Saarnio et al., 2014); these technologies are also used to measure carbonyl components in gas (Reda et al., 2015a, b), diesel engine combustion particles (Lyyränen et al., 2004; Burtscher, 2005; Fujitani et al., 2008), and gases and particles from coal-fired power plant exhaust or ship diesel engines (Streibel et al., 2017). However, these diluter types have some disadvantages, such as substantial particle loss due to long residence times and a turbulent flow 
during sampling (Desantes et al., 2011). Importantly, these diluters require sufficient high-pressure airflow to operate. However, most industrial facilities do not have adequate compressed-airflow supply systems for diluters.

In this study, we developed a new combined ejector and porous-tube diluter to continuously measure the particle size distribution at relatively low-airflow conditions compared to commercial diluters. To reduce particle loss in the diluter, the porous-tube was located as close as possible to the rear of the ejector. Dilution ratios and power consumption were compared at different airflow rates in the newly developed diluter and commercial porous-tube ejector-type diluter. The particle size distributions before and after dilution were also compared using fly ash particles at different dilution ratios and demonstrated from coal-fired power plant stack.

\section{METHODS}

Fig. 1(a) illustrates a schematic diagram of the commercial diluter (VC-DAS; Venacontra, Finland) tested in this study, which consisted of a porous-tube diluter (PRD) and ejector diluter (ED) in series. For sampling, a cyclone separator was installed on the front of the diluter to separate particles larger than $10 \mu \mathrm{m}$ to prevent blockage in the tube or damage to the particle-measuring instruments caused by the inflow of relatively large particles. Large particles within the cyclone are captured in the spiral airflow, and small particles are drawn into the diluter through the cyclone center. In the PRD, the dilution airflow is passed through a porous metal tube with $20-\mu \mathrm{m}$ pores to prevent the loss of sampled particles via attachment to the wall. The ED acts as a pump and uses the Venturi effect to transport fluids via suction using the pressure energy of fluids under high pressure $(\mathrm{Xu}$ et al., 2016). This process requires that the diluting air in the ED reaches a pressure of at least 4 bar. The inset in the Fig. 1 indicates the turbulent flow behind the ejector. Turbulence occurs in the diffuser when the internal angle exceeds $4-6^{\circ}$ and is caused by a sudden pressure change at the back of the ejector. Consequently, the sampled particles are subject to large sized particle loss due to this turbulence. In the commercial diluter, the sampling inlet flow rate $\left(\mathrm{Q}_{\mathrm{s}}\right)$, calculated with a flow meter between the PRD and ED, is expressed as the measured flow rate $\left(\mathrm{Q}_{\mathrm{M}}\right)$. $\mathrm{Q}_{\mathrm{ED}}$ and $\mathrm{Q}_{\mathrm{PRD}}$ are the flow rates supplied to ED and PRD, respectively. As shown in Fig. 1(a), Qs is calculated as follows:

$Q_{s}=Q_{M-} Q_{P R D}$

The dilution ratio for the commercial diluter is calculated using Eq. (2):

$$
\begin{aligned}
D R_{\text {commercial }} & =\frac{Q_{E D}+Q_{P R D}+Q_{S}}{Q_{S}}=\frac{Q_{E D}+Q_{P R D}+Q_{M}-Q_{P R D}}{Q_{M}-Q_{P R D}} \\
& =\frac{Q_{E D}+Q_{M}}{Q_{M}-Q_{P R D}}
\end{aligned}
$$

Fig. 1(b) illustrates a schematic diagram of the newly developed diluter used in this study, which combines an ED and PRD. In the developed diluter, the PRD is placed immediately behind the ED to prevent particle loss in the tube wall caused by turbulence at the back of the ED. The sampling inlet flow rate was measured using a flow meter placed in front of the ED. This flow was also expressed as the measured flow rate. In this case, however, $\mathrm{Q}_{\mathrm{S}}$ equals $\mathrm{Q}_{\mathrm{M}}$. Therefore, the final dilution ratio in the developed diluter is given by Eq. (3):

$$
D R_{\text {developed }}=\frac{Q_{E D}+Q_{P R D}+Q_{S}}{Q_{S}}=\frac{Q_{E D}+Q_{P R D}+Q_{M}}{Q_{M}}
$$

An air compressor (NCP052-T50; Air Maker, Korea) was used to supply diluting air to both the ED and PRD in the commercial diluter and the ED in the developed diluter. The air compressor has a tank volume of $50 \mathrm{~L}$, air-generating flow rate of $280 \mathrm{~L} \mathrm{~min}^{-1}$, and a maximum operating pressure of 8 bar. A ring blower (KJB3-400; Kijeonsa, Korea) was used to supply diluting air to the PRD in the developed diluter. The ring blower has a power consumption of $0.4 \mathrm{~kW}$, operating pressure of $1.2 \mathrm{bar}$, and a maximum flow rate of $2.4 \mathrm{~m}^{3} \mathrm{~min}^{-1}$. An oil trap, diffusion dryer, and high-efficiency particulate air (HEPA) filter were placed behind the compressor and ring blower to ensure that the air supplied for dilution was clean. The flow rate of the air supplied through the compressor was adjusted with a mass flow controller (MFC; Series 4800; Brooks Instrument, USA), and flow meters (Models 4040 and 4140; TSI Inc., USA) were used to measure the flow rates from the blower and sampling inlet.

The airflow rate required to obtain the same dilution ratio was compared between the diluters. Power consumption was also measured for $1 \mathrm{~h}$ by connecting the air suppliers used in each diluter to a power consumption measurement instrument (WT210; Yokogawa, Japan). The total power consumption $(\mathrm{kW})$ was given by the sum of the power consumed by the air supplier used in each diluter.

Fig. 2 shows a schematic diagram of the set-up used to measure the dilution ratio for each diluter. Fly ash was used as a test substance to determine the loss of particles due to dilution. The particles were supplied through a rotary feeder (Robo-Feeder MBST; Fine Technologies, Korea) placed in front of a $250 \times 250-\mathrm{mm}$ duct with a fluid flow velocity of $2.5 \mathrm{~m} \mathrm{~s}^{-1}$, which was measured using a vane-type flow meter (testo 400; Testo, Germany). The newly developed and commercial diluters were installed at the back of the duct to sample particles and measure them with optical instruments. An optical particle counter (Model 1.109; Grimm, Germany) was used to measure the concentration of particles from 0.25 to $32 \mu \mathrm{m}$ before and after dilution.

\section{RESULTS AND DISCUSSION}

Fig. 3 shows the dilution ratio of the commercial diluter according to the target PRD flow rate using a ring blower and compressor to supply the PRD dilution air. The ED dilution air was supplied by the compressor, and the flow 


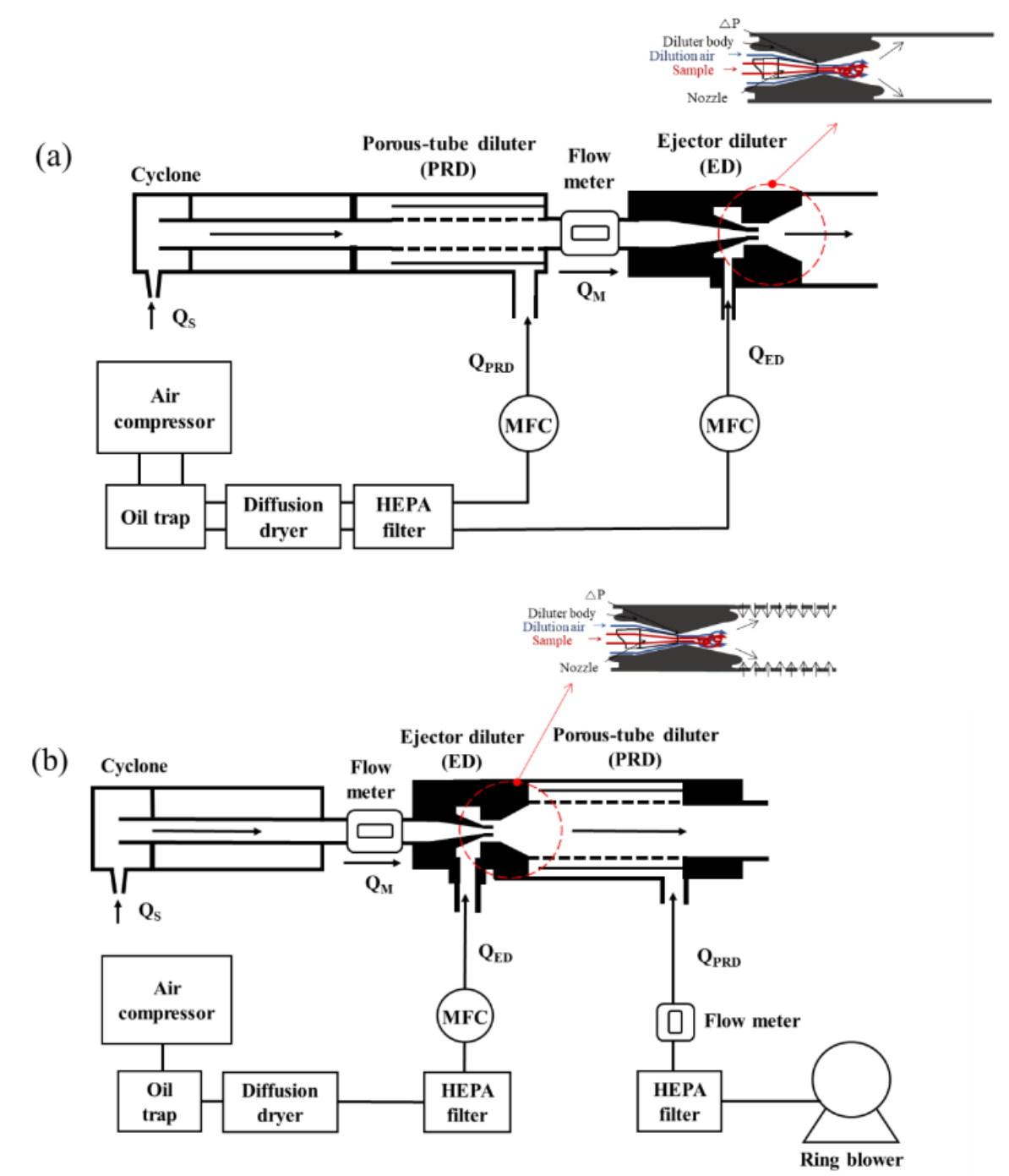

Fig. 1. Schematic of the experimental flow rate measurement set-up. (a) A commercial diluter and (b) the developed diluter. $M F C$ stands for "mass flow controller."

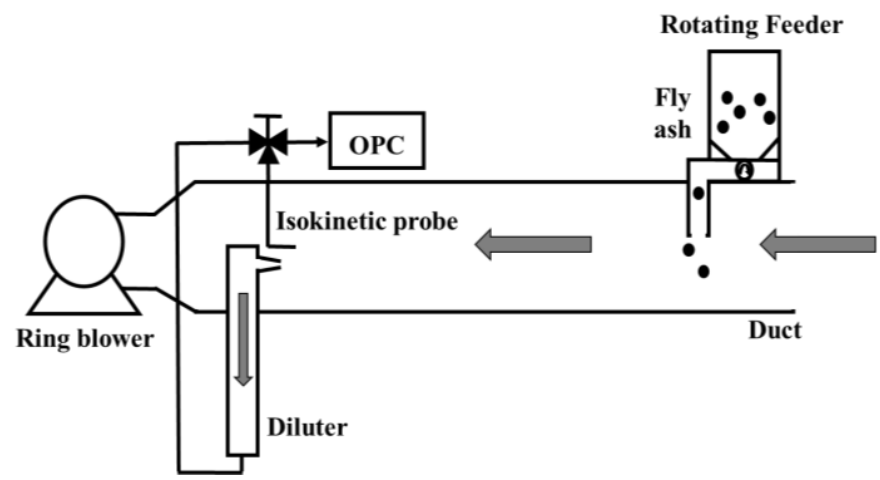

Fig. 2. Schematic of the particle dilution measurements in the two types of diluter. $O P C$ stands for "optical particle counter."

rate was fixed at $70 \mathrm{~L} \mathrm{~min}^{-1}$. When the air was supplied to the PRD using an air compressor, the dilution ratio increased when the set PRD flow rate increased from 0 to $20 \mathrm{~L} \mathrm{~min}^{-1}$.

However, using a ring blower allowed for a larger air supply at the target PRD flow rates of $0-10 \mathrm{~L} \mathrm{~min}^{-1}$ due to the suction power of the ED. The static pressure of air supplied through the ring blower is at atmospheric pressure, while that through the compressor can be supplied at the desired pressure. In this study, compressed air was supplied at 2 bar. This resulted in a higher dilution ratio compared to the set-up utilizing a compressor. Therefore, for the commercial diluter, it was difficult to control the dilution ratio when 


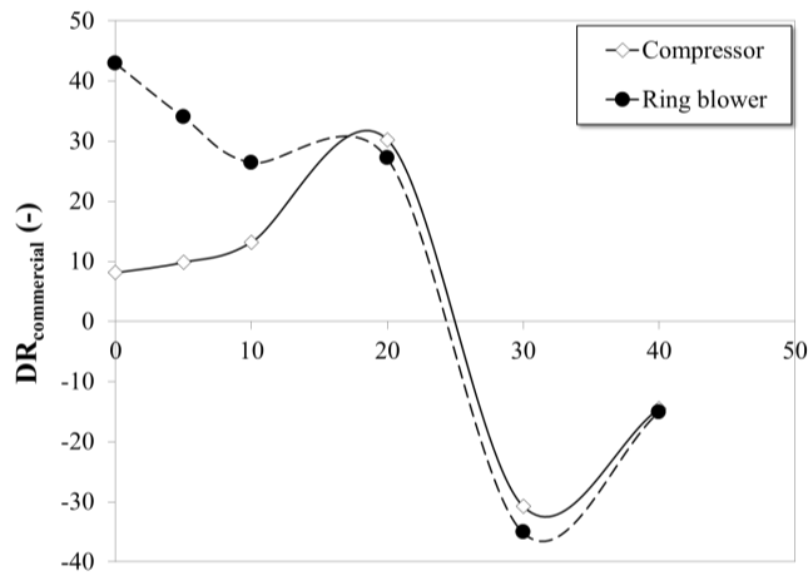

Target PRD flow rate $(\mathrm{L} / \mathrm{min})$

Fig. 3. Dilution ratio in the commercial diluter $\left(\mathrm{DR}_{\text {commercial }}\right)$ according to the target PRD flow rate with different air supply devices. PRD stands for "porous-tube diluter."

injecting diluted air into the PRD using the ring blower. Additionally, when the ED flow rate of the commercial diluter was $70 \mathrm{~L} \mathrm{~min}^{-1}$, the maximum flow rate into the PRD was $23 \mathrm{~L} \mathrm{~min}^{-1}$. When the PRD was supplied at a rate above $30 \mathrm{~L} \mathrm{~min}^{-1}$, only a fraction of the airflow supplied from the PRD entered the ED, and the remaining air was returned to the sampling inlet. For convenience, if the dilution airflow returned to the sampling inlet (i.e., Qs in Eq. (1)), it was designated as a negative value because $Q_{P R D}$ was larger than $\mathrm{Q}_{\mathrm{M}}$ in such cases. Thus, the negative dilution ratio in Fig. 3 indicates that particles from the stack could not enter the diluter and that clean dilution air was emitted through the sampling inlet. Therefore, if the flow rate to the ED was low, the flow rate supplied to the PRD also had to be low in order to sample the stack particles without a diluted air backflow, which may not work well for the PRD used to reduce particle loss. Conversely, if the PRD was located at the back of the ED, such as in the developed diluter, a change in the PRD flow rate did not significantly affect the sampling inlet flow rate, even if the ED flow rate was low. Furthermore, the suction power of the ED did not affect the PRD flow rate supplied by the ring blower, which allowed for the correct target flow rate to be supplied to the PRD. When diluters are used in the stacks of industrial combustion facilities, the use of compressed air at the site is very limited. Not only is there insufficient space for a large-capacity compressor, but it is also difficult to supply sufficient power. Thus, the use of the developed diluter and ring blowers has advantages. Using a ring blower instead of a high-pressure compressor to supply air to the PRD resulted in less power consumption for an equal airflow supply. The amount of dilution airflow required for the developed diluter can be minimized for added energy efficiency.

Fig. 4 shows the sampling inlet flow rate according to the ED and PRD flow rates of the newly developed and commercial diluters. For the developed diluter, the sampling inlet flow rate increased linearly with the ED flow rate, and it was affected by the ED flow rate regardless of the PRD

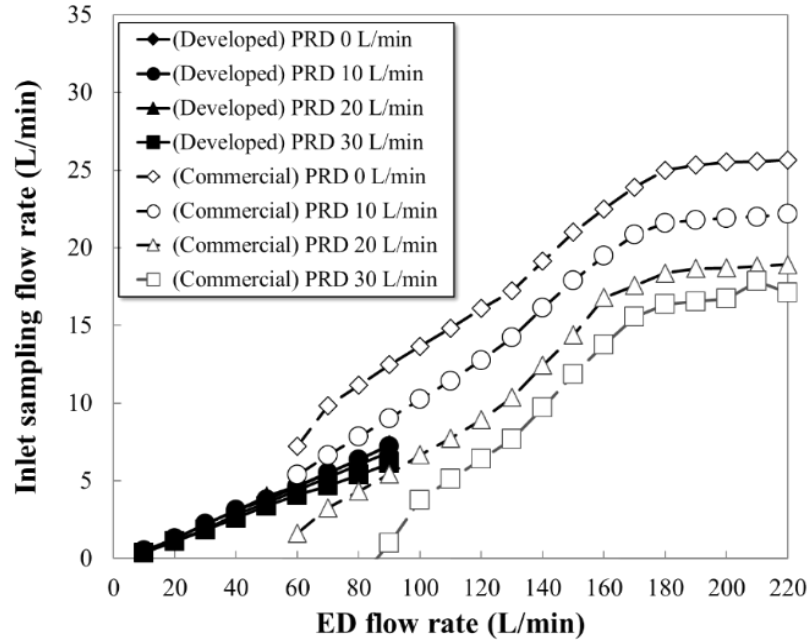

Fig. 4. Comparison of the inlet sampling flow rates at different flow rates supplied to the ejector (ED) and porous tube (PRD) of the two diluters.

flow rate. For the commercial diluter, the sampling inlet flow rate varied substantially depending on the PRD and ED flow rates. Therefore, it was necessary to carefully consider both the PRD and ED flow rates to achieve isokinetic sampling conditions.

Fig. 5 shows the dilution ratio at different ED flow rates when the newly developed and commercial diluters supplied $0,10,20$, and $30 \mathrm{~L} \mathrm{~min}^{-1}$ of dilution air to the PRD. To use a diluter in different environments, it must be possible to provide a wide range of dilution ratios. For the developed diluter, this could be accomplished using a low ED flow rate. For the commercial diluter, the ED flow rate had to be relatively high because the PRD was located in front of the ED. However, higher dilution airflows require more power. When airflow was supplied to the developed and commercial diluters through the compressor and the ring blower to obtain a dilution ratio of 18 , the power consumption of the commercial diluter was $583 \mathrm{~kW}$, which was approximately 2.1 times higher than the $280 \mathrm{~kW}$ required for the developed diluter.

To verify the dilution ratio, the experiment was also conducted with sulfur dioxide $\left(\mathrm{SO}_{2}\right)$ gas with the newly developed diluter. The initial gas concentration of $1000 \mathrm{ppm}$ was maintained using an $\mathrm{SO}_{2}$ mass flow controller, and the gas concentration was measured using a combined infrared method (VARIO PLUS; MRU Instruments, USA). The gas dilution ratio was expressed as the ratio of the gas concentration before and after dilution. Fig. 5(b) shows the comparison of the dilution ratio based on airflow rate and $\mathrm{SO}_{2}$ gas for the developed diluter. The gas-verified dilution ratio was within a $10 \%$ relative error, which indicates that the dilution ratio calculated from the ED and PRD flow rates was reliable. When the $\mathrm{Q}_{\mathrm{ED}}$ is $10 \mathrm{~L} \mathrm{~min}^{-1}$, the dilution ratio shows a large difference because the inlet sampling flow rate was too low to obtain an accurate measurement.

Fig. 6 shows the volume-dependent distribution according to particle size for the developed and commercial diluters at a given dilution ratio. To obtain a dilution ratio of approximately 
(a)

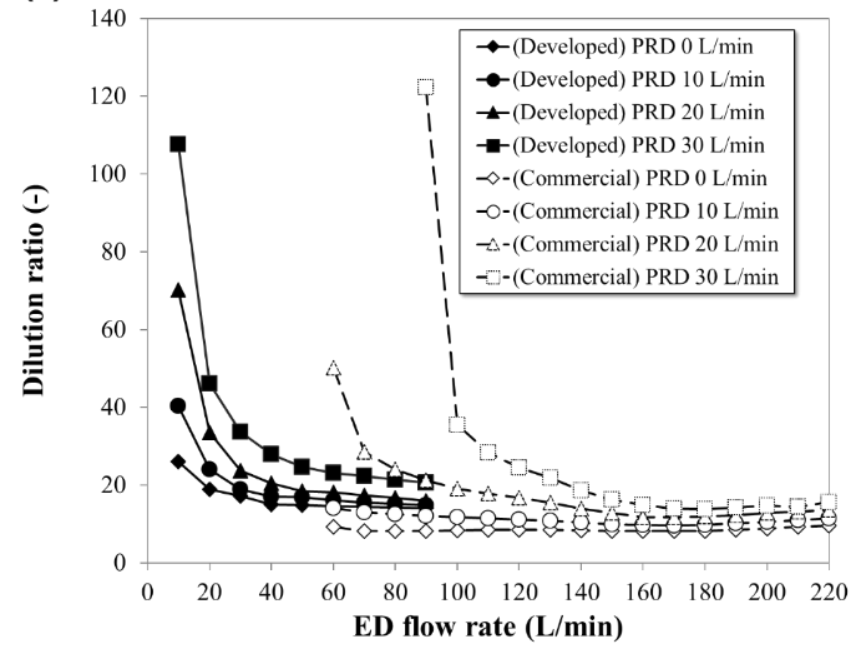

(b)

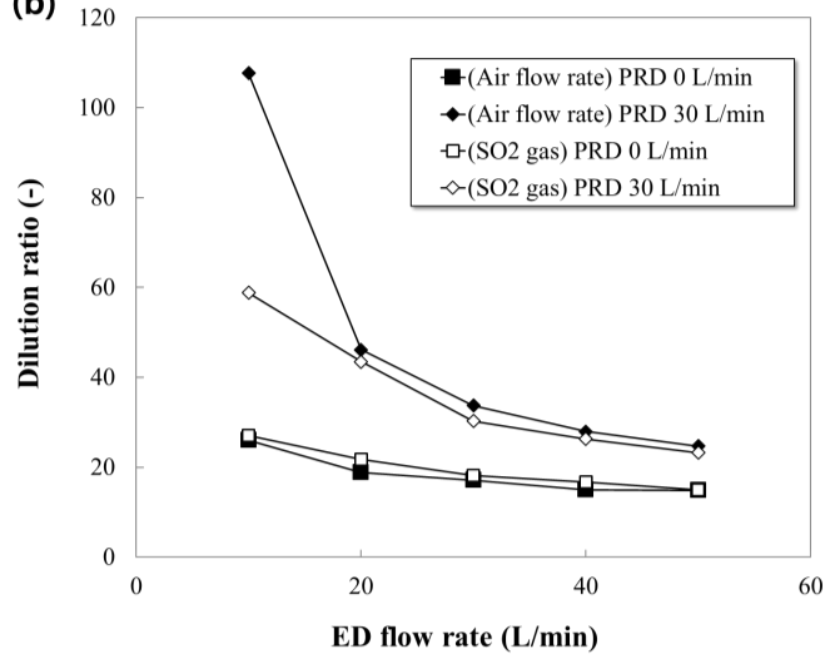

Fig. 5. Comparison of the dilution ratios using different flow rates supplied to the ejector (ED) and porous tube (PRD) of (a) the two diluters and (b) the developed diluter with dilution ratios calculated based on air flow rate and $\mathrm{SO}_{2}$ gas concentration.

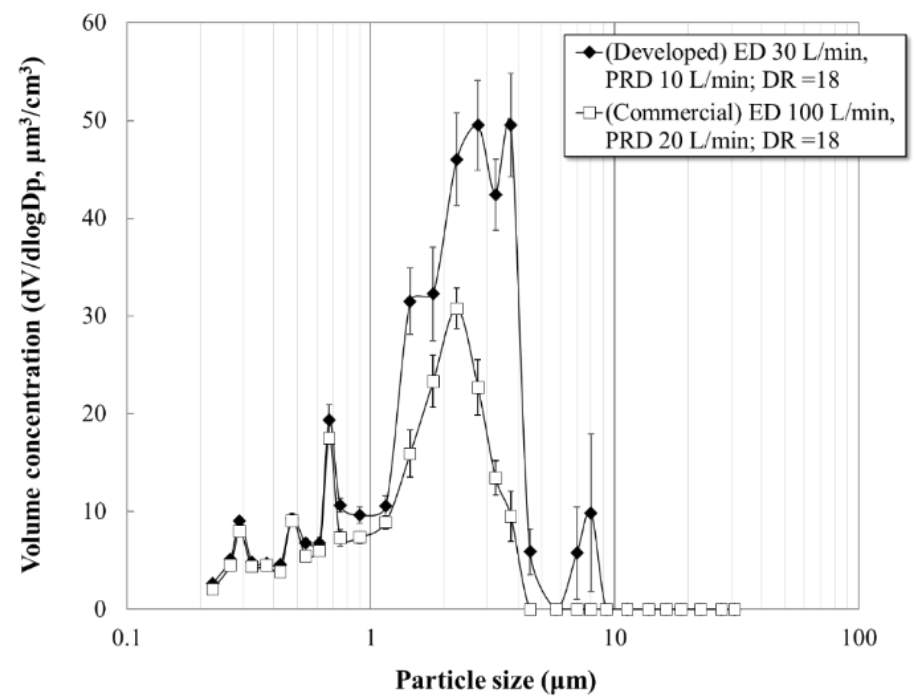

Fig. 6. Comparison of the particle volume distributions for the two diluters at a dilution ratio (DR) of 18 .

18 , the ED and PRD were supplied with flow rates of 30 and $10 \mathrm{~L} \mathrm{~min}^{-1}$ for the newly developed diluter and 100 and $20 \mathrm{~L} \mathrm{~min}^{-1}$ for the commercial diluter, respectively. Both diluters had mono-modal size distributions, with the mode diameter equal to approximately $2 \mu \mathrm{m}$. For particles less than $1 \mu \mathrm{m}$, the volume distributions of the two diluters were similar. However, for particles larger than $1 \mu \mathrm{m}$, the volume distribution of the developed diluter was approximately twice as high (especially for $2-\mu \mathrm{m}$-diameter particles) as that of the commercial diluter. This was because the PRD in the developed diluter prevented large sized particle losses that could occur behind the ED. At equal dilution ratios, the developed diluter had lower power consumption and lower particle losses than the commercial diluter.

Fig. 7 shows the change in volume distribution according to particle size before and after dilution at different PRD flow rates in each diluter. The size distributions after dilution shown in Fig. 7 were rescaled by multiplying them by each dilution ratio. As illustrated in Figs. 7(a) and 7(b), large particles over $10 \mu \mathrm{m}$ were completely eliminated by passing through the diluter, as they were removed through the inlet cyclone.

Fig. 7(a) shows the particle size volume distribution when the ED flow rate of the commercial diluter was fixed at 70 $\mathrm{L} \min ^{-1}$ and the PRD was $10 \mathrm{~L} \mathrm{~min}^{-1}$ or $20 \mathrm{~L} \mathrm{~min}^{-1}$, which was equivalent to dilution ratios of 9 and 24 , respectively. The diluters had similar concentrations for particles smaller than $1 \mu \mathrm{m}$, but a lower PRD flow rate resulted in a lower volume concentration for particles larger than $1 \mu \mathrm{m}$. In other words, if the PRD was not supplied with a sufficient flow rate, particle loss was not minimized; therefore, the PRD had to be supplied with an airflow rate of at least $20 \mathrm{~L} \mathrm{~min}^{-1}$. However, it was difficult to inject sufficient air to the PRD because reverse flow to the sampling inlet began to occur 
(a)

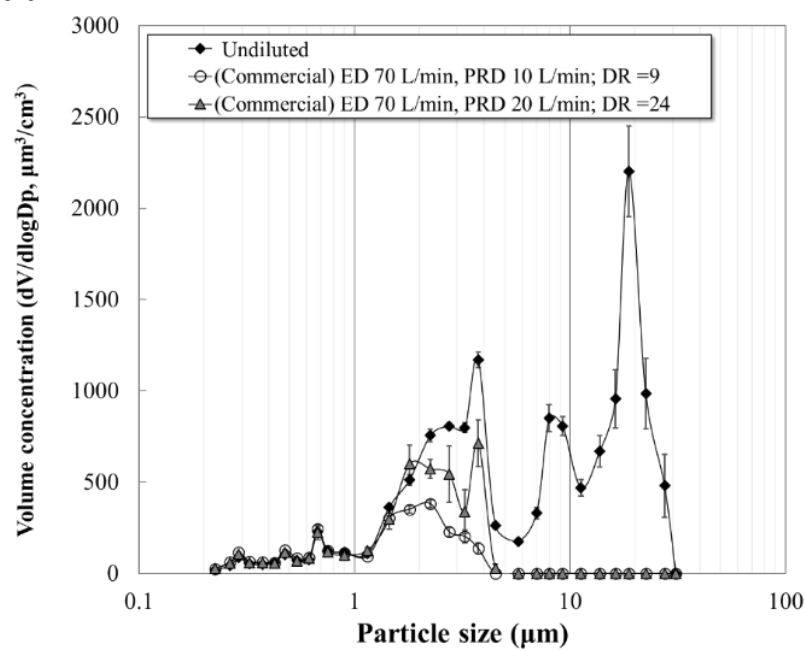

(b)

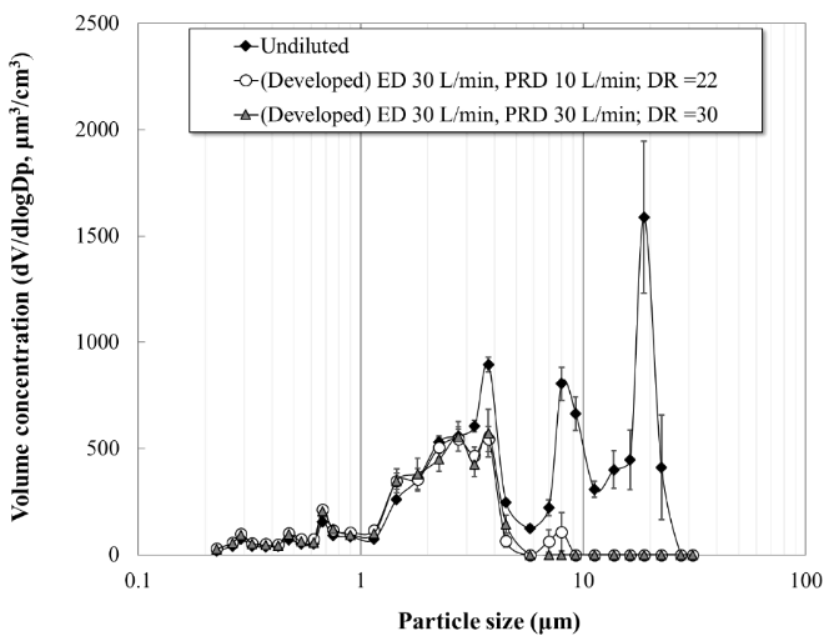

Fig. 7. Particle volume distribution changes in the porous-tube diluter flow rate for the (a) commercial diluter and (b) developed diluter. $D R$ stands for "dilution ratio," $E D$ stands for "ejector diluter," $P R D$ stands for "porous-tube diluter."

around $30 \mathrm{~L} \mathrm{~min} \mathrm{~m}^{-1}$, as explained in Fig. 3. Additionally, when the PRD flow rates were 10 and $20 \mathrm{~L} \mathrm{~min}^{-1}$, the volume concentrations of $\sim 2-\mu \mathrm{m}$ particles were 382 and $572 \mu \mathrm{m}^{3} \mathrm{~cm}^{-3}$, at which point the initial (undiluted) volume concentration was $756 \mu \mathrm{m}^{3} \mathrm{~cm}^{-3}$. The final volume concentration ratio was very high compared to that at the beginning (approximately 30-50\%).

Fig. 7(b) shows the particle size distribution when the ED flow rate of the newly developed diluter was fixed at $30 \mathrm{~L} \mathrm{~min}^{-1}$ and the PRD was $10 \mathrm{~L} \mathrm{~min}^{-1}$ and $30 \mathrm{~L} \mathrm{~min}^{-1}$, which was equivalent to dilution ratios of 22 and 30 , respectively. The developed diluter demonstrated a size distribution similar to that of the undiluted condition at sizes below $10 \mu \mathrm{m}$ because the PRD was located close to the back of the ED, preventing the loss of large particles. The developed diluter also showed similar distributions regardless of the flow rate supplied to the PRD. When the PRD flow rates were 10 and $30 \mathrm{~L} \mathrm{~min}^{-1}$, the volume concentrations of $\sim 2-\mu \mathrm{m}$ particles were 506 and $500 \mu \mathrm{m}^{3} \mathrm{~cm}^{-3}$ respectively, at which point the initial volume concentration was $532 \mu \mathrm{m}^{3} \mathrm{~cm}^{-3}$. The volume concentration ratio was reduced to under $10 \%$ at both PRD flow rates. Particles larger than approximately $2 \mu \mathrm{m}$ seem to show a large sized particle concentration decrease for both diluters. However, the decrease is probably caused by break-up of agglomerated fly ash during particle sampling and transport (Wong et al., 2010).

The diluter was bound to have particle losses due to particle transfer to the measurement device. Other losses are primarily due to non-isokinetic sampling, sedimentation, inertial impaction, and turbulent inertial deposition. Among these, inertial deposition was the largest particle-lossmechanism. Turbulent flow creates eddies, which causes curved streamlines towards the tube walls and potentially leads to particle deposition (Willeke and Baron, 2005). As particle size increases, particle inertia increases, which leads to increasing turbulent inertial deposition loss. Nevertheless, this confirms that combining the ejector and porous-tube diluter in series as in the developed diluter can minimize large-particle loss. Therefore, the developed diluter can potentially provide more reliable sampling compared to the commercial diluter when measuring $\mathrm{PM}_{2.5}$ and $\mathrm{PM}_{10}$.

The commercial diluter and the developed diluter were simultaneously tested at a coal-fired power plant in Taean located on the western side of South Korea, and the measurement results were compared (Fig. 8). Fig. 8 shows the $\mathrm{PM}$ concentration and $\mathrm{PM}_{1.0} / \mathrm{PM}_{2.5}$ continuously measured by the particle-measuring equipment (OPC) with the commercial diluter for $10 \mathrm{~min}$ and then with the developed diluter for $10 \mathrm{~min}$. These concentrations are diluted concentrations measured downstream of the diluters. In Fig. 8, the $\mathrm{PM}_{1.0}$ concentrations of the two diluters were different because different flow rates were supplied to each diluter for isokinetic sampling, and the particle sampling was performed under different dilution ratios. In the case of the commercial diluter, the $\mathrm{PM}_{10}, \mathrm{PM}_{2.5}$, and $\mathrm{PM}_{1.0}$ concentrations were approximately $15 \mu \mathrm{g} \mathrm{m}^{-3}$, at which

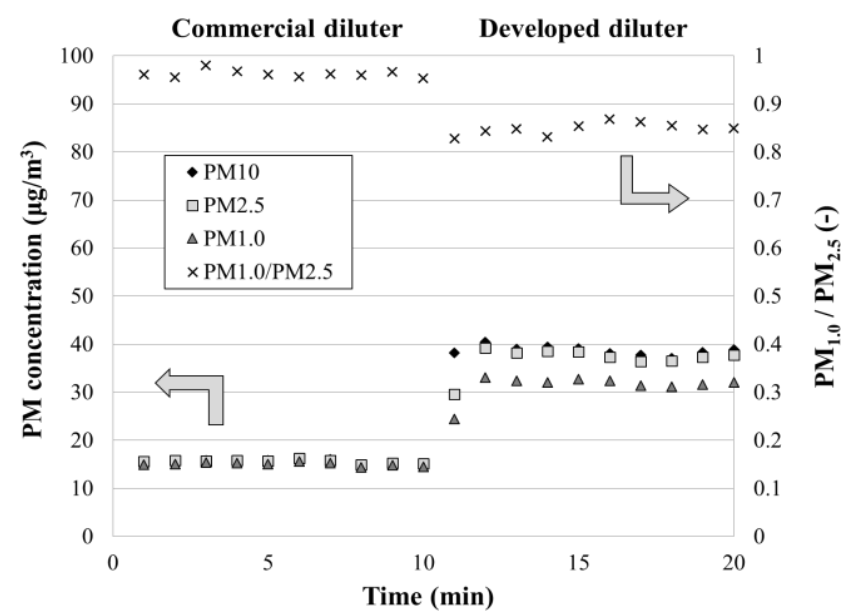

Fig. 8. Time-dependent particulate matter changes and $\mathrm{PM}_{1.0} / \mathrm{PM}_{10}$ ratios measured from a coal-fired power plant stack. 


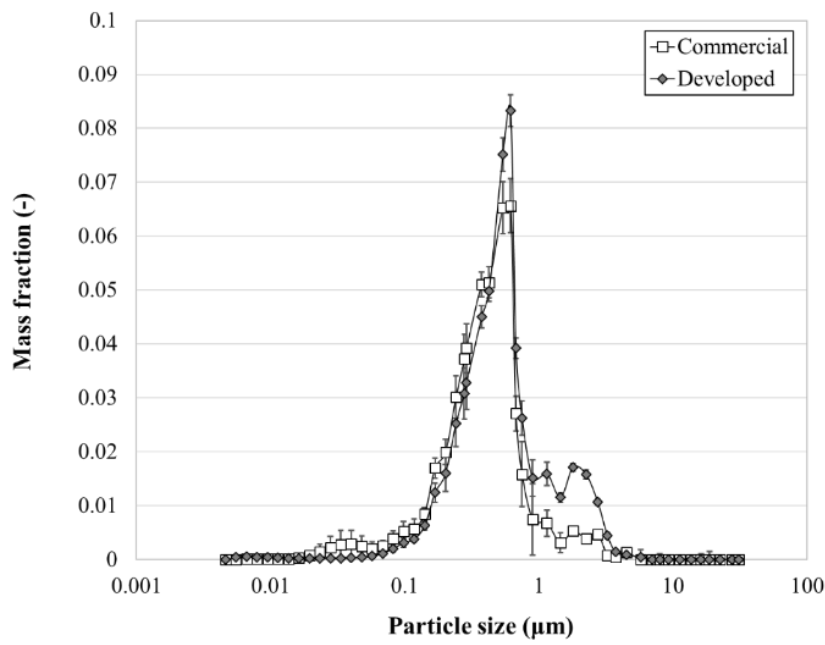

Fig. 9. Mass fraction measured in a coal-fired power plant stack according to particle size using the commercial and developed diluter.

point the $\mathrm{PM}_{1.0} / \mathrm{PM}_{2.5}$ ratio was 0.95 . This indicated that the $\mathrm{PM}_{1.0-10}$ concentration was considerably low. In the case of the developed diluter, the $\mathrm{PM}_{10}$ and $\mathrm{PM}_{2.5}$ concentrations were approximately $38 \mu \mathrm{g} \mathrm{m}^{-3}$, and the $\mathrm{PM}_{1.0}$ concentration was $32 \mu \mathrm{g} \mathrm{m}^{-3}$, at which point the $\mathrm{PM}_{1.0} / \mathrm{PM}_{2.5}$ ratio was 0.83. Fig. 9 shows the PM mass fraction distributions measured by the developed and commercial diluters at the coal-fired power plant in Taean. Mass distributions of particles less than $1.0 \mu \mathrm{m}$ for both the commercial and developed diluters are almost similar; however, those of particles larger than $1.0 \mu \mathrm{m}$ show a large difference. Fig. 9 demonstrates that particle loss is common for particles larger than $1 \mu \mathrm{m}$ but can be suppressed for the developed diluter in the field test, which is consistent with the laboratory measurements. The drastic generation of 30-50-nm particles as the effect of moisture (Damle et al., 1987) was suppressed by heating and diluting the sampled gas for the developed diluters.

\section{CONCLUSIONS}

We developed a novel ejector-porous tube diluter that enables a more accurate measurement of particle size distributions by minimizing particle loss and compared its performance to that of a commercial model. The commercial model, which requires relatively high-pressure and highflow-rate dilution air, consumed approximately 2.1 times as much power as our device when the dilution ratio was $\sim 18$. Because the inlet sampling flow rate of the developed diluter depends solely on the ED flow rate (regardless of the PRD), isokinetic sampling conditions were far easier to achieve. Furthermore, the diluter exhibited less than $\sim 10 \%$ particle loss for the fraction smaller than $2 \mu \mathrm{m}$ following dilution. The loss of larger particles $(2 \mu \mathrm{m}$ and above in diameter) was also significantly reduced compared to that of the commercial model, as confirmed via field testing.

In conclusion, the newly developed diluter minimizes large-particle loss and requires lower dilution airflow rates. Therefore, this device is a promising means of measuring particle size distributions in flue gas stacks.

\section{ACKNOWLEDGMENTS}

This work was supported by the Korea Institute of Energy Technology Evaluation and Planning (KETEP) and the Ministry of Trade, Industry \& Energy (MOTIE) of the Republic of Korea (Grant No. 20161110100140).

\section{REFERENCES}

Burtscher, H. (2005). Physical characterization of particulate emissions from diesel engines: A review. $J$. Aerosol Sci. 36: 896-932. https://doi.org/10.1016/j.jaero sci.2004.12.001

Chien, C.H., Theodore, A., Wu, C.Y., Hsu, Y.M. and Birky, B. (2016). Upon correlating diameters measured by optical particle counters and aerodynamic particle sizers. J. Aerosol Sci. 101: 77-85. https://doi.org/10.1016/j.jaer osci.2016.05.011

Damle, A.S., Ensor, D.S. and Sparks, L.E. (1987). Options for controlling condensation aerosols to meet opacity standards. JAPCA 37: 925-933. https://doi.org/10.1080/0 8940630.1987.10466286

Davidson, C.I., Phalen, R.F. and Solomon, P.A. (2005). Airborne particulate matter and human health: A review. Aerosol Sci. Technol. 39: 737-749. https://doi.org/10.10 80/02786820500191348

Desantes, J.M., Bermúdez, V., Molina, S. and Linares, W.G. (2011). Methodology for measuring exhaust aerosol size distributions using an engine test under transient operating conditions. Meas. Sci. Technol. 22: 115101. https://doi.org/10.1088/0957-0233/22/11/115101

Fujitani, Y., Hirano, S., Kobayashi, S., Tanabe, K., Suzuki, A., Furuyama, A. and Kobayashi, T. (2009). Characterization of dilution conditions for diesel nanoparticle inhalation studies. Inhalation Toxicol. 21: 200-209. https://doi.org/ 10.1080/08958370802339491

Kim, H. and Zhang, Q. (2019). Chemistry of new particle growth during springtime in the Seoul metropolitan area, Korea. Chemosphere 225: 713-722. https://doi.org/10.10 16/j.chemosphere.2019.03.072

Li, X., Wang, S., Duan, L., Hao, J. and Long, Z. (2011). Design of a compact dilution sampler for stationary combustion sources. J. Air Waste Manage. Assoc. 61: 1124-1130. https://doi.org/10.1080/10473289.2011.604556

Lipsky, E., Stanier, C.O., Pandis, S.N. and Robinson, A.L. (2002). Effects of sampling conditions on the size distribution of fine particulate matter emitted from a pilot-scale pulverized-coal combustor. Energy Fuels 16: 302-310. https://doi.org/10.1021/ef0102014

Lyyränen, J., Jokiniemi, J., Kauppinen, E.I., Backman, U. and Vesala, H. (2004). Comparison of different dilution methods for measuring diesel particle emissions. Aerosol Sci. Technol. 38: 12-23. https://doi.org/10.1080/0278682 0490247579

Mariam, Joshi, M., Khandare, P., Koli, A., Khan, A. and Sapra, B.K. (2017). Influence of sheath air humidity on measurement of particle size distribution by scanning 
mobility particle sizer. J. Aerosol Sci. 111: 18-25. https://doi.org/10.1016/j.jaerosci.2017.05.005

Reda, A.A., Czech, H., Schnelle-Kreis, J., Sippula, O., Orasche, J., Weggler, B., Abbaszade, G., Arteaga-Salas, J.M., Kortelainen, M., Tissari, J., Jokiniemi, J., Streibel, T. and Zimmermann, R. (2015a). Analysis of gas-phase carbonyl compounds in emissions from modern wood combustion appliances: Influence of wood type and combustion appliance. Energy Fuels 29: 3897-3907. https://doi.org/10.1021/ef502877c

Reda, A.A., Schnelle-Kreis, J., Orasche, J., Abbaszade, G., Lintelmann, J., Arteaga-Salas, J.M., Stengel, B., Rabe, R., Harndorf, H., Sippula, O., Streibel, T. and Zimmermann, R. (2015b). Gas phase carbonyl compounds in ship emissions: Differences between diesel fuel and heavy fuel oil operation. Atmos. Environ. 112: 370-380. https://doi.org/10.1016/j.atmosenv.2014.05.053

Saarnio, K., Frey, A., Niemi, J.V., Timonen, H., Rönkkö, T., Karjalainen, P., Vestenius, M., Teinilä, K., Pirjola, L., Niemelä, V., Keskinen, K., Häyrinen, A. and Hillamo, R. (2014). Chemical composition and size of particles in emissions of a coal-fired power plant with flue gas desulfurization. J. Aerosol. Sci. 73: 14-26. https://doi.org/10.1016/j.jaerosci.2014.03.004

Streibel, T., Schnelle-Kreis, J., Czech, H., Harndorf, H., Jakobi, G., Jokiniemi, J., Karg, E., Lintelmann, J., Matuschek, G., Michalke, B., Müller, L., Orasche, J., Passig, J., Radischat, C., Rabe, R., Reda, A., Rüger, C., Schwemer, T., Sippula, O., ... Zimmermann, R. (2017). Aerosol emissions of a ship diesel engine operated with diesel fuel or heavy fuel oil. Environ. Sci. Pollut. Res. 24: 10976-10991. https://doi.org/10.1007/s11356-016-6724-z

Willeke, K. and Baron, P.A. (2005). Aerosol measurement: Principles, techniques, and applications, Wiley, New York, N.Y., Chicheste.
Wong, C.P., Chan, T.L. and Leung, C.W. (2003). Characterisation of diesel exhaust particle number and size distributions using mini-dilution tunnel and ejectordiluter measurement techniques. Atmos. Environ. 37: 44354446. https://doi.org/10.1016/S1352-2310(03)00571-5

Wong, W., Fletcher, D.F., Traini, D. Chan, H.K., Crapper, J. and Young, P.M. (2010). Particle aerosolisation and break-up in dry powder inhalers 1: Evaluation and modelling of venturi effects for agglomerated systems. Pharm. Res. 20: 1367-1376. https://doi.org/10.1007/s11 095-010-0128-4

Woo, C.G., Hong, K.J., Kim, H.J., Kim, Y.J., Han, B., An, J. and Chun, S.N. (2017). Development and performance evaluation of the porous tube dilutor for real-time measurements of fine particles from high humidity environments. Part. Aerosol Res. 13: 105-110. (in Korean with English Abstract) https://doi.org/10.11629/j paar.2017.9.30.105

Wu, S.E., Hwang, K.J., Cheng, T.W., Tung, K.L., Iritani, E. and Katagiri, N. (2019). Structural design of a rotating disk dynamic microfilter in improving filtration performance for fine particle removal. J. Taiwan Inst. Chem. Eng. 94: 4352. https://doi.org/10.1016/j.jtice.2018.04.032

Zhang, Z., Wang, T., Jia, M., Wei, Q., Meng, X. and Shu, G. (2014). Combustion and particle number emissions of a direct injection spark ignition engine operating on ethanol/gasoline and n-butanol/gasoline blends with exhaust gas recirculation. Fuel 130: 177-188 https://doi.org/10.1016/j.fuel.2014.04.052

Received for review, March 25, 2020

Revised, June 30, 2020

Accepted, July 19, 2020 